\title{
The Impact of Determinants on Green Consumption Behavior for Green Design Displays
}

\author{
Chin-Hung Liu ${ }^{1} \&$ Jui-Lung Chen ${ }^{1}$ \\ ${ }^{1}$ Department of Business Administration, National Chin-Yi University of Technology, Taiwan \\ Correspondence: Chin-Hung Liu, Department of Business Administration, No.57, Sec.2, Zhongshan Rd., Taiping \\ Dist., Taichung City 41170, Taiwan. E-mail: chung1@ncut.edu.tw
}

Received: June 16, 2021

Accepted: July 2, 2021

Online Published: July 8, 2021

doi:10.5539/ijbm.v16n8p55

URL: https://doi.org/10.5539/ijbm.v16n8p55

\begin{abstract}
We conducted a consumer survey and used SPSS to examine the effects among technology acceptance model, theory of planned behavior, conformity and government low-carbon policies. The results of this study show that: 1. perceived usefulness and perceived ease-of-use have a significant and positive impact on green behavior attitude; green behavior attitude, green perceived behavior control, green subjective norms, and government low-carbon policies all have a significant and positive impact on green behavioral intention, and green behavioral intention also has a significant and positive impact on green consumption behavior. 2 . The normative and informational influences in conformity both have a significant and positive impact on green subjective norms, with normative influence exerting a greater impact. 3. On average, female consumers expressed a significantly higher agreement than male consumers with regard to the technology acceptance model, the theory of planned behavior, and conformity, and married consumers expressed a higher agreement than single and divorced consumers with regard to the technology acceptance model. The above results could provide companies with reference for development and business strategies involving sustainable displays.
\end{abstract}

Keywords: technology acceptance model, theory of planned behavior, conformity, government low-carbon policies, green consumption behavior

\section{Introduction}

With the advancement of technology and the huge consumption of natural resources during the modernization process, environmental pollution and resource depletion problems have worsened to the point that threatens the sustainability of the ecological system. According to HIS Markit's forecast, the global display market value is expected to exceed US $\$ 20.8$ billion by 2022 . Given such market demand, businesses need to incorporate green design considerations as early as in the product design stage to reduce the destruction of the natural environment while seeking to meet customer needs. Therefore, what are the key factors affecting customers' buying of green design displays is an issue worth investigating. In prior research of use, acceptance, and buying of technological products, the most extensively applied theories include Theory of Reasoned Action (TRA) proposed by Fishbein and Ajzen in 1975, Theory of Planned Behavior (TPB) proposed by Ajzen in 1985, and Technology Acceptance Model (TAM) proposed by Davis in 1989. In most applications, these theories have also shown considerable effectiveness in explaining and predicting users' acceptance behavior. Conformity behavior refers to individual behaviors that are affected by group norms. When living with a group of people, individuals will inevitably interact with others and have a tendency to align their thoughts or behaviors with group norms and expectations in order to establish group identity and avoid the risk of being excluded. Therefore, consumers may match their beliefs to group norms and act in similar ways as other members of the group (Hsiung, 2014).

Besides, in the society, individual behaviors are much influenced by policies set forth by the government. It has been empirically confirmed that whether a policy or subsidy implemented by the government meets consumers' expectations has a significant effect on consumers' behavioral intention (Shen, 2003). How to identify the factors affecting consumer behaviors and develop technological products that not only comply with green design concepts but also attract consumer adoption is an issue that deserves discussion. To sum up, this study is motivated to analyze the effects of variables in TAM and TPB along with conformity and the government's low-carbon policy on consumers' buying of green design displays. The objective of this study is to identify the key factors affecting consumers' intention to buy green design displays and explore how to incorporate green 
design concepts to promote green consumption behavior.

\section{Literature Review}

\subsection{A Brief Introduction of the Development of Display Devices}

The development of displays began in 1897 when German scientist Braun introduced the first cathode ray tube (CRT) scanning device. Later in 1929, Westinghouse unveiled the world's first black-and-white CRT television. CRT television is large in size and bulky. It is not suitable for application in portable products (Hu, 2018). With the continuous advancement of technology, flat panel displays were introduced to the market after 2000. Characterized by a lighter weight, lower power consumption, and higher portability, flat panel displays gradually took the place of CRT systems. Flat panel displays refer to many types of non-CRT displays, including liquid crystal display (LCD), plasma display panel (PDP), organic light-emitting diode (OLED and PLED), and Micro LED display. LCD is the dominant type of flat panel display in today's market, and Micro LED is expected to be the next-generation display technology after 2018 (LEDinside, 2018).

\subsection{Green Design and Green Design Displays}

Green design is also called environmental design or ecological design. Green design is a design process that involves people's reflection on the destruction of the environment caused by modern technology and culture and designers' reflection of their social responsibilities and moral values on their creations. The objective of green design is to minimize environmental pollution through reduced use of natural resources and raw materials and to consider all the possible environmental effects of a product throughout its lifecycle from production to sell, use, and disposal in the design stage (Yeh, 2007).

Green design display refers to display devices that are designed and manufactured based on the green design concepts such as reduce use of natural resources, minimize environmental pollution, and consider the convenience of disassembly and recyclability of products at end-of-life (Tu, 2009). The Environmental Protection Administration, Executive Yuan, has released "Guidelines for Promotion of Green Consumption and Environmental Protection Products" as a foundation for certifying green design products. Products which have passed the certification will be awarded the Environmental Label (Ecolabel) that can be printed on the products or their packages to help consumers identify their compliance with regulations. The effect of Ecolabels is also within the scope of analysis in this study.

\subsection{Technology Acceptance Model (TAM)}

Technology Acceptance Model (TAM) is a model adapted from Theory of Reasoned Action (TRA) to explain the factors affecting users' acceptance of new information technologies (Davis, 1989). According to the models developed or adapted by Davis (1989), Yang (2012), Chiao (2015), Hsu (2016), and Huang (2017), this study identifies five key variables of TAM and modifies three of them as "Attitude toward green behavior", "Green behavioral intention", and "Green consumption behavior". Based on these variables, this study will explore how users' attitude toward green behavior is reinforced by perceived usefulness and perceived ease of use to further affect their green behavioral intention and green consumption behavior.

\subsection{Theory of Planned Behavior (TPB)}

Theory of Planned Behavior (TPB) was developed from TRA. It differs from TRA in its addition of perceived behavioral control in the theoretical model. It proposes that when one plans to perform a specific behavior, he or she will evaluate his or her ability to perform the given behavior based on past experiences (Ajzen, 1991). According to Ajzen's model (1991) and the models adapted by Chen (2012) and Chen (2012), this study identifies five variables of TPB, including attitude, subjective norm, perceived behavioral control, behavioral intention, and behavior. Based on the research question, this study modifies these variables as "Attitude toward green behavior", "Green subjective norm", "Perceived control of green behavior", "Green behavioral intention", and "Green consumption behavior". Based on these variables, this study will explore how attitude toward green behavior, green subjective norm, and perceived control of green behavior affect green behavioral intention and green consumption behavior.

\subsection{Conformity Behavior}

Conformity behavior refers to changing or maintaining personal behavior due to the influence of other members in the group. It has been defined as a tendency to align personal beliefs or behaviors with the norms and expectations of other members of the group in order to fit in with the group (Huang, 2016). This study explores the impact of conformity behavior on consumers based on the definitions and arguments proposed by Huang (2013), Huang (2016), and Kuo (2016). According to these studies, consumers may also have a higher tendency 
to buy green products when people important to them or other members of their social group are more supportive of green products. In this study, two types of conformity behavior are considered, namely "Informational conformity" and "Normative conformity". How these two types of conformity behavior respectively affect consumers' behavioral buying of low-carbon products will be examined.

\subsection{The Government's Low-Carbon Policy}

Government policy refers to the important measures planned and implemented by the government in a bid to increase the competitiveness of a specific industry (Liu, 2008). To promote products with the EU Ecolabel, European Union (EU) has formulated a series of standards and guidelines for businesses to follow. On one hand, businesses will be more motivated to research, develop, and manufacture products that comply with the EU Ecolabel; on the other, consumers will also place more trust in products carrying the EU Ecolabel and have higher intention to buy them (Chung, 2011). The measures of government policy proposed by Liu (2008), Chung (2011), and Chen (2016) are adopted and modified to fit the "Government's low-carbon policy" dimension of this study. Based on these measures, this study will analyze the degree to which the government's low carbon policy affects consumers' green behavioral intention and how to promote consumers' green consumption behavior

\section{Research Framework and Method}

\subsection{Research Framework}

This research framework combines technology acceptance model, theory of planned behavior, conformity, government low-carbon policies, and green behavior intentions to explore the impact between the above factors on green consumption behavior of consumers who purchase green design displays. In the technology acceptance model, this research is based on the five dimensions of technology acceptance model proposed and applied by Davis (1989), Yang (2012), Jiao (2015), Hsu (2016), and Huang (2017). The five dimensions are perceived usefulness, perceived ease of use, behavior attitude, behavior intention, and actual use behavior. Three of these above dimensions including behavior attitude, behavior intention, and actual use behavior are revised to be green behavior attitude, green behavior intention and green consumption behavior, respectively. Therefore, the perceived usefulness, perceived ease of use, green behavior attitude, green behavior intention, and green consumption behavior are used as the dimensions of technology acceptance model in this research. In assessment of theory of planned behavior, the five dimensions of theory of planned behavior developed and proposed and applied by Ajzen (1991), Chen (2012), and Chen (2012) respectively. The five dimensions include attitude, subjective norm, and perceived behavior control, behavioral intention, and behavior. The above dimensions are revised to be green behavior attitude, green subjective norm, green perceived behavior control, green behavioral intention, and green consumption behavior, which are used as the dimensions of theory of planned behavior in this study. Moreover, in conformity behavior, this study applies the informational conformity and normative conformity dimensions proposed and used by Huang (2013), Huang (2016), and Guo (2016) as the two dimensions of conformity behavior. In addition, regarding the government's low carbon policy, the questionnaires for measuring the government's low-carbon policy proposed and used by Liu (2008), Chung (2011), and Chen (2016) are revised as the measurement questionnaire items of the government's low-carbon policy in this study.

According to the above-mentioned literature contents, the research framework is developed to explore the impact between the technology acceptance model, theory of planned behavior, conformity behavior, and government's low-carbon policy on green consumption behaviors of consumers who purchase low-carbon products, and we will also examine if perceptions of the technology acceptance model, theory of planned behavior, conformity behavior, and government's low-carbon policy differ by demographic variables. Therefore, the following research framework developed by this study is shown in Figure 1.

\subsection{Research Hypothesis}

This study develops the following nine research hypotheses based on the research purpose, literature review and research framework, as shown in Table 1. 


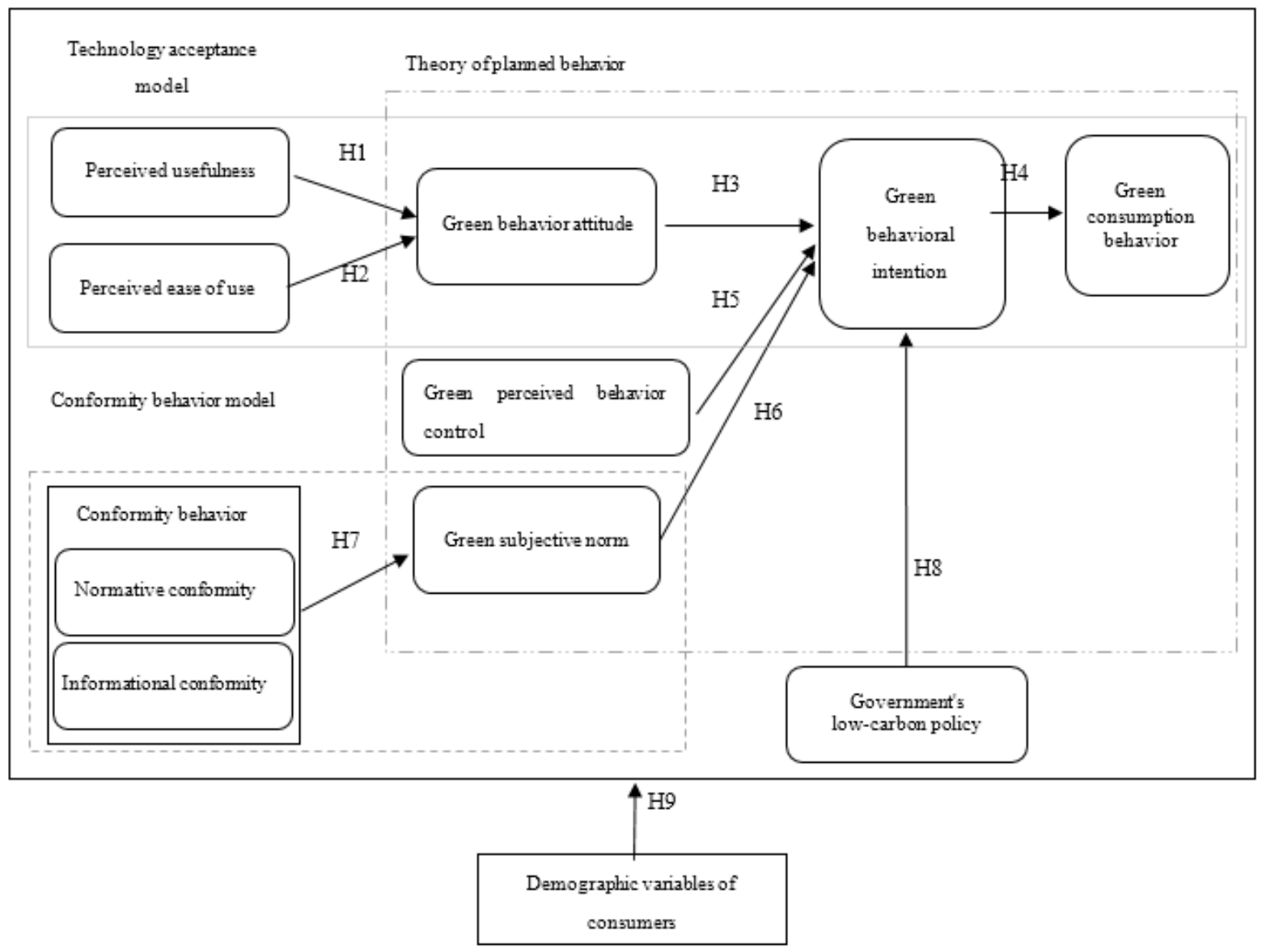

Figure 1. Research Framework

Table 1. Summary of research hypotheses

\begin{tabular}{|c|c|}
\hline Hypothesis & Contents \\
\hline Hypothesis $1(\mathrm{H} 1)$ & Perceived usefulness has a significant positive impact on green behavior attitude. \\
\hline Hypothesis $2(\mathrm{H} 2)$ & Perceived ease of use has a significant positive impact on green behavior attitude. \\
\hline Hypothesis 3 (H3) & Green behavior attitude has a significant positive impact on green behavioral intention. \\
\hline Hypothesis 4 (H4) & Green behavioral intention has a significant positive impact on green consumption behavior. \\
\hline Hypothesis 5 (H5) & Green perceived behavior control has a significant positive impact on green behavioral intention. \\
\hline Hypothesis 6 (H6) & Green subjective norm has a significant positive impact on green behavioral intention. \\
\hline Hypothesis 7 (H7) & Conformity behavior has a significant positive impact on green subjective norm. \\
\hline Hypothesis 8 (H8) & Government's low-carbon policy has a significant positive impact on green behavioral intention. \\
\hline Hypothesis 9 (H9) & $\begin{array}{l}\text { Demographic variables have differences in the perceptions of the technology acceptance model, theory of } \\
\text { planned behavior, conformity behavior, and government's low-carbon policy. }\end{array}$ \\
\hline
\end{tabular}

\subsection{Sampling Design}

The survey of the questionnaire was implemented in two stages. The first stage was the pre-test of the questionnaire. The distribution period of the questionnaires was from October 25, 2018 to November 7, 2018. It was distributed in the form of an anonymous questionnaire, and a total of 24 questionnaires were collected. There were 21 acceptable questionnaires and 3 unacceptable questionnaires. After the acceptable questionnaires 
were collected, SPSS software was used for data analysis, and then the reliability of the questionnaire was tested based on the reliability analysis to modify or delete the contents of the questionnaire items. The second stage was a formal questionnaire survey. The distribution period was from November 15, 2018 to March 31, 2019. After the questionnaires were collected, the acceptable questionnaires were utilized to test the hypotheses of this study by the statistical analysis methods. A total of 436 questionnaires were surveyed in this study, including 301 online questionnaires and 135 paper questionnaires. Finally, a total of 361 acceptable questionnaires were obtained, and the acceptable response rate was $82.80 \%$.

\section{Data Analysis and Results}

This study uses statistical software SPSS as the data analysis tool, and the analysis method of the data applies eight statistical analysis methods including descriptive statistical analysis, reliability analysis, one sample t-test analysis, correlation analysis, factor analysis, simple linear and multiple regression analyses, Independent sample $\mathrm{t}$-test analysis, and One-way analysis of variance.

\subsection{Descriptive Statistical Analysis}

The distributions of the demographic variables of the questionnaires are obtained through descriptive statistical analysis. The analysis results show that the sample consists of mainly males; respondents aged between 30 and 40 make up the largest age group; married respondents take a larger ratio than other groups; most respondents have a university/college degree, work in the manufacturing/industrial sectors, have a monthly income between $\$ 30,001$ and $\$ 40,000$, and currently reside in central regions of Taiwan. In addition, when making a purchase decision, most of them would prioritize green design displays with a label showing that it is able to meet the requirements of environmental protection such as reusable or recyclable.

\subsection{Reliability Analysis}

The Cronbach's $\alpha$ value is utilized as the reliability measure, and the Cronbach's $\alpha$ coefficients and correlation coefficients between revised items and overall items are applied to measure the internal consistency of the questionnaires in this study. The coefficient value is higher between the above two, and it means the measurement has more stable and consistent characteristics. The relative reliability value would also be higher. The overall reliability coefficient of this study was 0.945 by the reliability analysis. The reliability analysis of perceived usefulness, perceived ease-of-use, green behavior attitude, green behavioral intention, and green consumption behavior indicates that the overall reliability coefficients of Cronbach's $\alpha$ are $0.864,0.872,0.878$, 0.875 , and 0.885 for the values respectively, and the overall reliability coefficient of Cronbach's $\alpha$ is 0.878 for theory of planned behavior; the reliability coefficients of Cronbach's $\alpha$ of green perceived behavior control and green subjective norm are 0.828 and 0.865 respectively; the overall reliability coefficient of Cronbach's $\alpha$ is 0.916 for conformity behavior, and the reliability coefficients of Cronbach's $\alpha$ of normative conformity and informational conformity are 0.912 and 0.876 respectively; the overall reliability coefficient of Cronbach's $\alpha$ is 0.873 for government's low-carbon policy. The reliability values of this study are quite high because the reliability coefficients of the survey are all greater than 0.8 (Hair et al., 2006).

\subsection{One Sample T-Test Analysis}

The one sample t-test analysis is utilized to test null hypothesis $H_{0}$ : the mean of population $(\mu) \leqq 3$, while alternative hypothesis $\mathrm{H} 1: \mu>3$, which is used to analyze the survey of consumers for questionnaire items of TAM (technology acceptance model), TPB (theory of planned behavior), conformity behavior, and government's low-carbon policy, and it indicates to have the distribution situation of agreement or strong agreement.

\subsection{Correlation Analysis}

This research explores the correlation among the TAM (technology acceptance model), TPB (theory of planned behavior), conformity behavior, and government's low-carbon policy through Pearson correlation analysis. In the TAM, under the significant level of $\alpha=0.01$, the $\mathrm{p}$ values between the TAM with TPB, conformity behavior, and government's low-carbon policy are 0.000 less than $\alpha=0.01$ by the correlation analysis, all of which have the significance. The correlation coefficients of them are $0.789,0.685$, and 0.737 respectively, which represents that there have high positive correlations among them. Therefore, there are significantly positive correlations among the TAM with TPB, conformity behavior, and government's low-carbon policy, that is: The higher the agreement of consumer for the TAM, the higher the agreement of consumer for TPB, conformity behavior, and government's low-carbon policy. In the TPB, under the significant level of $\alpha=0.01$, the $p$ values between the TPB with conformity behavior and government's low-carbon policy are 0.000 less than $\alpha=0.01$, all of which have the significance. The correlation coefficients of them are 0.730 and 0.664 respectively, which represents that there have high positive correlations between them. Therefore, there are significantly positive correlations 
between the TPB with conformity behavior and government's low-carbon policy, which shows: The higher the agreement of consumer for the TPB, the higher the agreement of consumer for conformity behavior and government's low-carbon policy. Finally, in the conformity behavior, under the significant level of $\alpha=0.01$, the $\mathrm{p}$ value between the conformity behavior and government's low-carbon policy is 0.000 less than $\alpha=0.01$, which has the significance. The correlation coefficients of them is 0.574 , which indicates that there has a moderate positive correlation between them. Therefore, there is a significantly positive correlation between the conformity behavior and government's low-carbon policy, which represents: The higher the agreement of consumer for the conformity behavior, the higher the agreement of consumer for government's low-carbon policy. In summary, there are significantly positive correlations among the TAM, TPB, conformity behavior, and government's low-carbon policy.

\subsection{Factor Analysis}

\subsubsection{Factor Analysis of TAM}

This study is to determine whether the TAM is suitable for factor analysis before performing a factor analysis of the TAM. The factor analysis is utilized to extract common factors between questionnaire items. The value of KMO sampling adequacy test is 0.940 , which is close to 1 . The approximate Chi-square distribution value of the Bartlett sphere test is 5552.094, and $p=0.000$ is significant, which shows that it has the significance. The 25 survey items of the TAM have common factors, and they are suitable for factor analysis (Kaiser, 1974; Wu, 2015). The factor analysis procedure of this study involves use of the principal component analysis to retain common factors with an eigenvalue greater than 1 and the varimax rotation analysis. The scale develops based on TAM consists of 25 items. Through factor analysis, five dimensions are extracted. The cumulative variance explained by these five dimensions is $67.923 \%$, satisfying the $>60 \%$ criterion. The rotated results are also consistent with those obtained from the original dimensions and items. The dimensions of each factor are extracted and illustrated in the following:

Dimension 1: Items No. 7, 8, 9, 6, and 10 suggest that, for consumers, a product that is easy to learn, use and master its functions and built with a user-friendly interface is important. This dimension is named "Perceived ease of use". Dimension 2: Items No. 22, 23, 24, 21, and 25 suggest that, these items evaluate users' actual adoption of green products under the influence of other variables. This dimension is named "Green consumption behavior". Dimension 3: Items No. 2, 3, 1, 4, and 5 suggest that, these items evaluate the degree to which consumers believe that the given product is more advanced in terms of design and technology, is able to reduce more energy consumption and pollution, and can create greater economic benefits than the products it is replacing. This dimension is named "Perceived usefulness". Dimension 4: Items No. 14, 13, 15, 11, and 12 suggest that, these items evaluate consumers' attitude toward green products, which is a mixture of positive and negative views and perceptions of green consumption. This dimension is named "Green behavior attitude". Dimension 5: Items No. 19, 18, 16, 20, and 17 suggest that, these items evaluate a person's perceived likelihood that he or she will engage in green consumption. This dimension is named "Green behavioral intention".

\subsubsection{Factor Analysis of TPB}

This study is to determine whether the TPB is suitable for factor analysis before performing a factor analysis of the TAM. The factor analysis is utilized to extract common factors between questionnaire items. The value of KMO sampling adequacy test is 0.880 , which is close to 1 . The approximate Chi-square distribution value of the Bartlett sphere test is 1659.091 , and $p=0.000$ is significant, which shows that it has the significance. The 10 survey items of the TPB have common factors, and they are suitable for factor analysis. The factor analysis procedure of this study involves use of the principal component analysis to retain common factors with an eigenvalue greater than 1 and the varimax rotation analysis. The scale develops based on TPB consists of 10 items. Through factor analysis, two dimensions are extracted. The cumulative variance explained by these two dimensions is $63.330 \%$, satisfying the $>60 \%$ criterion. The rotated results are also consistent with those obtained from the original dimensions and items. The dimensions of each factor are extracted and illustrated in the following:

Dimension 1: Items No. 32, 31, 33, 34, and 35 suggest that, these items evaluate the degree to which an individual believes that people important to him or her or members of a social group support a certain green behavior or the degree to which an individual believes his or her decision to engage in a green behavior is affected by social pressures or perceptions. This dimension is named "Green subjective norm". Dimension 2: Items No. 28, 27, 30, 29, and 26 suggest that, these items evaluate an individual's perceived control over the opportunity to and resources for buying green products. This dimension is named "Green perceived behavior control". 


\subsubsection{Factor Analysis of Conformity Behavior}

This study is to determine whether the conformity behavior is suitable for factor analysis before performing a factor analysis of the conformity behavior. The factor analysis is utilized to extract common factors between questionnaire items. The value of KMO sampling adequacy test is 0.916 , which is close to 1 . The approximate Chi-square distribution value of the Bartlett sphere test is 2300.428 , and $p=0.000$ is significant, which shows that it has the significance. The 10 survey items of the conformity behavior have common factors, and they are suitable for factor analysis. The factor analysis procedure of this study involves use of the principal component analysis to retain common factors with an eigenvalue greater than 1 and the varimax rotation analysis. The scale develops based on conformity behavior consists of 10 items. Through factor analysis, two dimensions are extracted. The cumulative variance explained by these two dimensions is $70.573 \%$, satisfying the $>60 \%$ criterion. The rotated results are also consistent with those obtained from the original dimensions and items. The dimensions of each factor are extracted and illustrated in the following:

Dimension 1: Items No. 38, 37, 36, 39, and 40 suggest that, these items imply that when one finds that the attitude or behavior of the group matches with his or her value, he or she may internalize the norms of the group and show conformity behaviors. This dimension is named "Normative conformity". Dimension 2: Items No. 43, $44,42,41$, and 45 suggest that, these items imply that when one feels confused and uncertain when making a decision, he or she may accept the information provided by the group and then change his or her original behavior or purchase decision. This dimension is named "Informational conformity".

\subsubsection{Factor Analysis of Government's Low-Carbon Policy}

This study is to determine whether the government's low-carbon policy is suitable for factor analysis before performing a factor analysis of the government's low-carbon policy. The factor analysis is utilized to extract common factors between questionnaire items. The value of KMO sampling adequacy test is 0.865 , which is close to 1. The approximate Chi-square distribution value of the Bartlett sphere test is 828.567 , and $p=0.000$ is significant, which shows that it has the significance. The 5 survey items of the government's low-carbon policy have common factors, and they are suitable for factor analysis. The factor analysis procedure of this study involves use of the principal component analysis to retain common factors with an eigenvalue greater than 1 and the varimax rotation analysis. The scale develops based on government's low-carbon policy consists of 5 items. Through factor analysis, one dimension is extracted. The cumulative variance explained by the one dimension is $66.354 \%$, satisfying the $>60 \%$ criterion. The rotated result is also consistent with that obtained from the original dimension and items. The dimension of this factor is extracted and illustrated in the following:

Dimension: Items No. 46, 50, 48, 47, and 49 suggest that, these items suggest that in order to develop a strategic industry or foster the development of new technologies, the government will implement a series of policies, such as providing subsidies for carbon reduction, to increase consumers' usage intention and the competitiveness of the industry. This dimension is named "Government's low-carbon policy".

\subsection{Simple Linear and Multiple Regression Analyses}

\subsubsection{Simple Linear Regression Analysis of the Impact of Perceived Usefulness on Green Behavior Attitude}

The standardized regression equation is shown that green behavior attitude $=0.628 *$ perceived usefulness through the simple linear regression analysis. Green behavior attitude is utilized as the dependent variable, and perceived usefulness is used as independent variables. This research applies a simple linear regression analysis to examine the effect of perceived usefulness on the green behavior attitude. The analytical results indicate that the explanation ability of variables of the overall model is 0.393 after $\mathrm{R}^{2}$ adjusted, showing that the perceived usefulness could explain the variance of $39.3 \%$ of the green behavior attitude. In the test of significance, $F$ value is $233.949(\mathrm{p}=0000)$ and significant, suggesting the regression result is statistically meaningful. The standardized $\beta$ coefficient for the relationship between perceived usefulness and green behavior attitude is 0.628 ( $t=15.295$. $\mathrm{p}=0.000$ ), as shown in Table 2. Overall, the results indicate that perceived usefulness is positively and significantly related to green behavior attitude. Therefore, $\mathrm{H} 1$ is supported. 
Table 2. The impact of perceived usefulness on green behavior attitude

\begin{tabular}{|c|c|c|c|c|c|}
\hline \multirow{2}{*}{ Model } & Standardized coefficients & \multirow{2}{*}{$\mathrm{R}^{2}$} & \multirow{2}{*}{ Adjusted $\mathrm{R}^{2}$} & \multirow{2}{*}{$\mathrm{t}$} & \multirow{2}{*}{ Significance } \\
\hline & Beta distribution & & & & \\
\hline ( Constant) & & & & 9.464 & $0.000 * * *$ \\
\hline Perceived usefulness & 0.628 & 0.395 & 0.393 & 15.295 & $0.000^{* * *}$ \\
\hline
\end{tabular}

Note. Dependent variable $=$ green behavior attitude; $* * * \mathrm{p} \leq 0.001$.

\subsubsection{Simple Linear Regression Analysis of the Impact of Perceived Ease of Use On Green Behavior Attitude}

The standardized regression equation is shown that green behavior attitude $=0.454 *$ perceived ease of use through the simple linear regression analysis. Green behavior attitude is utilized as the dependent variable, and perceived ease of use is used as independent variables. This research applies a simple linear regression analysis to examine the effect of perceived ease of use on the green behavior attitude. The analytical results indicate that the explanation ability of variables of the overall model is 0.204 after $\mathrm{R}^{2}$ adjusted, showing that the perceived ease of use could explain the variance of $20.4 \%$ of the green behavior attitude. In the test of significance, $F$ value is $93.334(p=0000)$ and significant, suggesting the regression result is statistically meaningful. The standardized $\beta$ coefficient for the relationship between perceived ease of use and green behavior attitude is $0.454(t=9.661$, $\mathrm{p}=0.000$ ), as shown in Table 3. Overall, the results indicate that perceived ease of use is positively and significantly related to green behavior attitude. Therefore, $\mathrm{H} 2$ is supported.

Table 3. The impact of perceived ease of use on green behavior attitude

\begin{tabular}{cccccc}
\hline Model & $\begin{array}{c}\text { Standardized coefficients } \\
\text { Beta distribution }\end{array}$ & $\mathrm{R}^{2}$ & Adjusted $\mathrm{R}^{2}$ & $\mathrm{t}$ & Significance \\
\hline $\begin{array}{c}\text { ( Constant) } \\
\text { Perceived usefulness }\end{array}$ & 0.454 & & & 14.084 & $0.000^{* * *}$ \\
\hline
\end{tabular}

Note. Dependent variable $=$ green behavior attitude; $* * * \mathrm{p} \leq=0.001$.

4.6.3 Simple Linear Regression Analysis of the Impact of Green Behavior Attitude on Green Behavioral Intention

The standardized regression equation is shown that green behavioral intention $=0.661 *$ green behavior attitude through the simple linear regression analysis. Green behavioral intention is utilized as the dependent variable, and green behavior attitude is used as independent variables. This research applies a simple linear regression analysis to examine the effect of green behavior attitude on the green behavioral intention. The analytical results indicate that the explanation ability of variables of the overall model is 0.436 after $\mathrm{R}^{2}$ adjusted, showing that the green behavior attitude could explain the variance of $43.6 \%$ of the green behavioral intention. In the test of significance, $\mathrm{F}$ value is $279.092(\mathrm{p}=0000)$ and significant, suggesting the regression result is statistically meaningful. The standardized $\beta$ coefficient for the relationship between green behavior attitude and green behavioral intention is $0.661(\mathrm{t}=16.706, \mathrm{p}=0.000)$, as shown in Table 4. Overall, the results indicate that green behavior attitude is positively and significantly related to green behavioral intention. Therefore, H3 is supported.

Table 3. The impact of green behavior attitude on green behavioral intention

\begin{tabular}{ccccc}
\hline Model & $\begin{array}{c}\text { Standardized coefficients } \\
\text { Beta distribution }\end{array}$ & $\mathrm{R}^{2}$ & Adjusted R $^{2}$ & $\mathrm{t}$ \\
\hline $\begin{array}{c}\text { (Constant) } \\
\text { Green behavior attitude }\end{array}$ & 0.661 & & 8.347 & $0.000^{* * *}$ \\
\hline
\end{tabular}

Note. Dependent variable $=$ green behavioral intention; $* * * \mathrm{p} \leq 0.001$. 
4.6.4 Simple Linear Regression Analysis of the Impact of Green Behavioral Intention on Green Consumption Behavior

The standardized regression equation is shown that green consumption behavior $=0.687^{*}$ green behavioral intention through the simple linear regression analysis. Green consumption behavior is utilized as the dependent variable, and green behavioral intention is used as independent variables. This study applies a simple linear regression analysis to examine the effect of green behavioral intention on the green consumption behavior. The analytical results indicate that the explanation ability of variables of the overall model is 0.470 after $\mathrm{R}^{2}$ adjusted, showing that the green behavioral intention could explain the variance of $47.0 \%$ of the green consumption behavior. In the test of significance, $F$ value is $320.862(\mathrm{p}=0000)$ and significant, suggesting the regression result is statisticallv meaningful. The standardized $\beta$ coefficient for the relationship between green behavioral intention and green consumption behavior is $0.687(\mathrm{t}=17.913, \mathrm{p}=0.000)$, as shown in Table 5. Overall, the results indicate that green behavioral intention is positively and significantly related to green consumption behavior. Therefore, H4 is supported.

Table 5. The impact of green behavioral intention on green consumption behavior

\begin{tabular}{cccccc}
\hline Model & $\begin{array}{c}\text { Standardized } \\
\text { coefficients } \\
\text { Beta distribution }\end{array}$ & $\mathrm{R}^{2}$ & Adjusted $\mathrm{R}^{2}$ & $\mathrm{t}$ & Significance \\
\hline (Constant) & & & 11.075 & $0.000^{* * *}$ \\
Green behavioral intention & 0.687 & 0.472 & 0.470 & 17.913 & $0.000^{* * *}$ \\
\hline
\end{tabular}

Note. Dependent variable $=$ green consumption behavior; $* * * \mathrm{p} \leq 0.001$.

4.6.5 Simple Linear Regression Analysis of the Impact of Green Perceived Behavior Control on Green Behavioral Intention

The standardized regression equation is shown that green behavioral intention $=0.679 *$ green perceived behavior control through the simple linear regression analysis. Green behavioral intention is utilized as the dependent variable, and green perceived behavior control is used as independent variables. This research applies a simple linear regression analysis to examine the effect of green perceived behavior control on the green behavioral intention. The analytical results indicate that the explanation ability of variables of the overall model is 0.459 after $\mathrm{R}^{2}$ adjusted, showing that the green perceived behavior control could explain the variance of $45.9 \%$ of the green behavioral intention. In the test of significance, $F$ value is $306.598(\mathrm{p}=0000)$ and significant, suggesting the regression result is statistically meaningful. The standardized $\beta$ coefficient for the relationship between green perceived behavior control and green behavioral intention is $0.679(t=17.510 \cdot p=0.000)$, as shown in Table 6. Overall, the results indicate that green perceived behavior control is positively and significantly related to green behavioral intention. Therefore, $\mathrm{H} 5$ is supported.

Table .6. The impact of green perceived behavior control on green behavioral intention

\begin{tabular}{|c|c|c|c|c|c|}
\hline Model & $\begin{array}{c}\text { Standardized } \\
\text { coefficients } \\
\text { Beta distribution }\end{array}$ & $\mathrm{R}^{2}$ & Adjusted $\mathrm{R}^{2}$ & $\mathrm{t}$ & Significance \\
\hline$($ Constant $)$ & & & & 7.558 & $0.000 * * *$ \\
\hline $\begin{array}{l}\text { Green perceived behavior } \\
\text { control }\end{array}$ & 0.679 & 0.461 & 0.459 & 17.510 & $0.000 * * *$ \\
\hline
\end{tabular}

Note. Dependent variable $=$ green behavioral intention; $* * * \mathrm{p} \leq 0.001$.

\subsubsection{Simple Linear Regression Analysis of the Impact of Green Subjective Norm on Green Behavioral Intention}

The standardized regression equation is shown that green behavioral intention $=0.679 *$ green subjective norm through the simple linear regression analysis. Green behavioral intention is utilized as the dependent variable, and green subjective norm is used as independent variables. This research applies a simple linear regression analysis to examine the effect of green subjective norm on the green behavioral intention. The analytical results indicate that the explanation ability of variables of the overall model is 0.365 after $\mathrm{R}^{2}$ adjusted, showing that the green subjective norm could explain the variance of $36.5 \%$ of the green behavioral intention. In the test of 
significance, $\mathrm{F}$ value is $208.010(\mathrm{p}=0000)$ and significant, suggesting the regression result is statistically meaningful. The standardized $\beta$ coefficient for the relationship between green subjective norm and green behavioral intention is $0.606(\mathrm{t}=14.423 \cdot \mathrm{p}=0.000)$, as shown in Table 7. Overall, the results indicate that green subjective norm is positively and significantly related to green behavioral intention. Therefore, H6 is supported.

Table 7. The impact of green subjective norm on green behavioral intention

\begin{tabular}{cccccc}
\hline Model & $\begin{array}{c}\text { Standardized } \\
\text { coefficients } \\
\text { Beta distribution }\end{array}$ & $\mathrm{R}^{2}$ & Adjusted $\mathrm{R}^{2}$ & $\mathrm{t}$ & Significance \\
\hline $\begin{array}{c}\text { (Constant) } \\
\text { Green subjective norm }\end{array}$ & 0.606 & 0.367 & 0.365 & 13.286 & $0.000^{* * *}$ \\
\hline
\end{tabular}

Note. Dependent variable $=$ green behavioral intention; $* * * \mathrm{p} \leq 0.001$.

\subsubsection{Multiple Regression Analysis of the Impact of Conformity Behavior on Green Subjective Norm}

The standardized regression equation is shown that green subjective norm $=0.491 *$ normative conformity + $0.334 *$ informational conformity through the multiple regression analysis. Green subjective norm is utilized as the dependent variable, and normative conformity and informational conformity are used as independent variables. This study applies a multiple regression analysis to explore the impact of normative conformity and informational conformity on the green subjective norm. This research performs a collinearity analysis in order to test the independence of each predictive variable. According to the analytical results, the all values of VIF are 1.632 less than 10 , which shows the two tolerances $(0.613,0.613)$ of the independent variables could meet the required benchmarks without collinearity problems. The independent variables of this research have no collinearity, which indicates it could utilize multiple regression analysis. The analytical results indicate that the explanation ability of variables of the overall model is 0.553 after $\mathrm{R}^{2}$ adjusted, indicating that the conformity behavior could explain the variance of $55.3 \%$ of the green subjective norm. The F-value of $224.101(\mathrm{p}=0.000)$ in the overall measure of significance is significant and shows the regression impact with the statistical significance. Besides, the standardized coefficient $\beta$ of normative conformitv for the green subjective norm is $0.491(\mathrm{t}=10.904, \mathrm{p}=0.000)$ and the standardized coefficient $\beta$ of informational conformity for the green subjective norm is $0.334(\mathrm{t}=7.421, \mathrm{p}=0.000)$. As shown in Table 8 , green subjective norm is most significantly affected by "Normative conformity", followed by "Informational conformity". The result of this study shows that "Normative conformity" and "Informational conformity" are all positively and significantly related to green subjective norm. Therefore, $\mathrm{H} 7$ is supported.

Table 7 The impacts of normative conformity and informational conformity on green subjective norm

\begin{tabular}{ccccccc}
\hline Model & $\begin{array}{c}\text { Standardized } \\
\text { coefficients } \\
\text { Beta distribution }\end{array}$ & $\mathrm{R}^{2}$ & Adjusted $\mathrm{R}^{2}$ & $\mathrm{t}$ & Significance & VIF \\
\hline (Constant) & & & & 6.836 & $0.000^{* * *}$ & \\
Normative conformity & 0.491 & \multirow{2}{*}{0.556} & 0.553 & 10.904 & $0.000^{* * *}$ & 1.632 \\
Informational conformity & 0.334 & & 7.421 & $0.000^{* * *}$ & 1.632 \\
\hline
\end{tabular}

Note. Dependent variable $=$ green subjective norm; $* * * \mathrm{p} \leq 0.001$.

4.6.8 Simple Linear Regression Analysis of the Impact of Government's Low-Carbon Policy on Green Behavioral Intention

The standardized regression equation is shown that green behavioral intention $=0.663 *$ government's low-carbon policy through the simple linear regression analysis. Green behavioral intention is utilized as the dependent variable, and government's low-carbon policy is used as independent variables. This research applies a simple linear regression analysis to examine the effect of government's low-carbon policy on the green behavioral intention. The analytical results indicate that the explanation ability of variables of the overall model is 0.438 after $\mathrm{R}^{2}$ adjusted, showing that the government's low-carbon policy could explain the variance of $43.8 \%$ of the green behavioral intention. In the test of significance, $F$ value is $281.594(\mathrm{p}=0000)$ and significant, 
suggesting the regression result is statisticallv meaningful. The standardized $\beta$ coefficient for the relationship between government's low-carbon policy and green behavioral intention is $0.663(\mathrm{t}=16.781 \cdot \mathrm{p}=0.000)$, as shown in Table 8. Overall, the results indicate that government's low-carbon policy is positively and significantly related to green behavioral intention. Therefore, $\mathrm{H} 8$ is supported.

Table 8. The impact of government's low-carbon policy on green behavioral intention

\begin{tabular}{cccccc}
\hline Model & $\begin{array}{l}\text { Standardized } \\
\text { coefficients } \\
\text { Beta distribution }\end{array}$ & $\mathrm{R}^{2}$ & Adjusted $\mathrm{R}^{2}$ & $\mathrm{t}$ & Significance \\
\hline (Constant) & & & & 7.922 & $0.000^{* * *}$ \\
Government's low-carbon policy & 0.663 & 0.440 & 0.438 & 16.781 & $0.000^{* * *}$ \\
\hline
\end{tabular}

Note. Dependent variable $=$ green behavioral intention; $* * * \mathrm{p} \leq 0.001$.

\subsection{Independent Sample T-Test Analysis}

This study explores and analyzes the difference between the sample means of two independent populations with the same variance.

4.7.1 The Difference in Perception of "Gender" on the TAM, TPB, Conformity Behavior, and Government's Low-Carbon Policy

This research examines the difference in perception of "Gender" on the TAM, TPB, conformity behavior, and government's low-carbon policy by independent sample t-test analysis. The results of this study show that there are gender differences in perceptions of the effects of variables from TAM and TPB and conformity behavior. More specifically, with regard to the perception of the effects of variables from TAM and TPB and the effect of conformity behavior, the average agreement degree is significantly higher among female consumers than among male consumers.

4.7.2 The Difference in Perception of "Marital Status" on the TAM, TPB, Conformity Behavior, and Government's Low-Carbon Policy

This research explores the difference in perception of "Marital status" on the TAM, TPB, conformity behavior, and government's low-carbon policy, and it utilizes Levene test analysis with the same population variances. The result of homogeneity test indicates that "marital status" is a significant factor affecting consumers' perception of the TAM. On average, married respondents scored significantly higher on this dimension than unmarried and divorced ones.

\subsection{One-Way Analysis of Variance}

4.8.1 The Difference in Perception of "Age" on the TAM, TPB, Conformity Behavior, and Government's Low-Carbon Policy

According to the results of the homogeneity test of population variance, the p-values of age on the TAM, TPB, conformity behavior, and government's low-carbon policy are $0.225,0.580,0.792$, and 0.210 , respectively, and they are greater than $\alpha=0.05$ at the significance level $\alpha=0.05$. Therefore, it is suitable for one-way analysis of variance. The $p$-values are $0.188,0.762,0.398$, and 0.309 , respectively, which are all greater than $\alpha=0.05$, and it represents that consumers of different ages have no significant differences in perception of the TAM, TPB, conformity behavior, and government's low-carbon policy through on one-way analysis of variance.

4.8.2 The Difference in Perception of "Education Level" on the TAM, TPB, Conformity Behavior, and Government's Low-Carbon Policy

According to the results of the homogeneity test of population variance, the p-values of education level on the conformity behavior, and government's low-carbon policy are 0.101 and 0.693 , respectively, and they are greater than $\alpha=0.05$ at the significance level $\alpha=0.05$. Therefore, it is suitable for one-way analysis of variance. It represents that consumers of different education levels have significant differences in perception of the conformity behavior and government's low-carbon policy through on one-way analysis of variance. In addition, Scheffe's multiple comparison test shows that consumers with a university/college degree score significantly higher on the effect of conformity behavior than consumers with a master/doctorate degree, and but consumers' perceptions of the effect of the government's low-carbon policy do not significantly differ between education degrees. 
4.8.3 The Difference in Perception of "Occupation" on the TAM, TPB, Conformity Behavior, and Government's Low-Carbon Policy

According to the results of the homogeneity test of population variance, the p-values of occupation on the TPB and conformity behavior are 0.205 and 0.619 , respectively, and they are greater than $\alpha=0.05$ at the significance level $\alpha=0.05$. Therefore, it is suitable for one-way analysis of variance. The $p$-values are 0.792 and 0.954 , respectively, which are all greater than $\alpha=0.05$, and it represents that consumers of different occupations have no significant differences in perception of the TPB and conformity behavior by on one-way analysis of variance.

4.8.4 The Difference in Perception of "Place of Residence" on the TAM, TPB, Conformity Behavior, and Government's Low-Carbon Policy

According to the results of the homogeneity test of population variance, the p-values of place of residence on the conformity behavior, and government's low-carbon policy are $0.071,0.206$, and 0.736 , respectively, and they are greater than $\alpha=0.05$ at the significance level $\alpha=0.05$. Therefore, it is suitable for one-way analysis of variance. It represents that consumers of different places of residence have significant differences in perception of the conformity behavior through on one-way analysis of variance. In addition, Scheffe's multiple comparison test shows that consumers who live in the central region score significantly higher on the effect of conformity behavior than consumers who live in the northern and other regions.

4.8.5 The Difference in Perception of "Average Monthly Income" on the TAM, TPB, Conformity Behavior, and Government's Low-Carbon Policy

According to the results of the homogeneity test of population variance, the p-values of average monthly income on the TAM, TPB, conformity behavior, and government's low-carbon policy are $0.314,0.267,0.097$, and 0.095 , respectively, and they are greater than $\alpha=0.05$ at the significance level $\alpha=0.05$. Therefore, it is suitable for one-way analysis of variance. The p-values are $0.230,0.285,0.644$, and 0.530 , respectively, which are all greater than $\alpha=0.05$, and it represents that consumers with different average monthly incomes have no significant differences in perception of the TAM, TPB, conformity behavior, and government's low-carbon policy by on one-way analysis of variance.

The above result of this research indicates that some of demographic variables have various differences in perception on the TAM, TPB, conformity behavior, and government's low-carbon policy. Therefore, H9 is partially supported.

\section{Conclusions and Management Implications}

\subsection{Conclusions}

This study uses consumers as the research object. It explores the impacts between the TAM, TPB, conformity behavior, and government's low-carbon policy, and verifies whether the demographic variables of different consumers have significant differences in perception of the TAM, TPB, conformity behavior, and government's low-carbon policy or not through the questionnaire surveys and SPSS statistical software tool. According to the results of this study, it will be able to provide a reference for the related display industry to apply the green design as their operating strategies. The conclusions of this research are summarized in the following:

5.1.1 The Results of Simple Linear Regression and Multiple Regression Analysis Are Described in the Following 1. The "Perceived usefulness" and "Perceived ease of use" all have significantly positive effects on the green behavior attitude. The "Green behavior attitude", "Green perceived behavior control", "Green subjective norm", and "Government's low-carbon policy" all have significantly positive impacts on the green behavioral intention. In addition, the "Green behavioral intention" also has a significantly positive effect on the green consumption behavior.

2. The "Normative conformity" and "Informational conformity" of conformity behavior all have significantly positive effects on the green subjective norm. Moreover, the "Normative conformity" has the most significant effect on the green subjective norm.

\subsubsection{The Results of Independent Sample T-Test Analysis Are Explained in the Following}

1. Consumers who have the various genders would have significant differences in perception on the TAM, TPB, and conformity behavior, and the average agreement level of female consumers has significantly higher than that of male them for the TAM, TPB, and conformity behavior.

2. Consumers who have the various marital statuses would have significant differences in perception on the TAM, and the average agreement level of married consumers has significantly higher than that of unmarried and 


\section{divorced them for the TAM.}

\subsubsection{The Results Shown by One-Way Analysis of Variance Are Illustrated as Follows}

1. In the education level, consumers with a university/college degree have a significantly higher agreement level of the conformity behavior than that of those with a master/doctorate degree.

2. In the place of residence, consumers who live in the central region have a significantly higher agreement level of the conformity behavior than that of those who live in the northern and other regions.

The summary of the above analytical results is indicated that there are all significantly positive effects between the TAM, TPB, conformity behavior, and government's low-carbon policy. Besides, consumers with the different genders have significant differences in perceptions of the TAM, TPB, and conformity behavior, and those with the various marital statuses have all significant differences in perception of the TAM, and those with the different education levels and places of residence also have significant differences in perception of the conformity behavior.

\subsection{Management Implications}

This study considers the dimensions in TAM and TPB, conformity behavior, and government's low-carbon policy to explore the differences in perceptions of the effects of these dimensions on green consumption behavior across demographic variables and the impact among these dimensions. Based on findings, this study proposes the following suggestions:

\subsubsection{Analysis of the Impact Among the Research Dimensions}

1. Results indicate that among the dimensions of TAM, both "Perceived usefulness" and "Perceived ease of use" have a positive and significant impact on "Green behavior attitude"; "Green behavior attitude" has a positive and significant effect on "Green behavioral intention"; "Green behavioral intention" has also a positive and significant impact on "Green consumption behavior". These findings suggest that businesses should adopt green design concepts as early as in the initial stage of product development. For instance, they can adopt a simple and user-friendly interface to shorten the time needed to learn how to use the product. Moreover, they can explain the concepts and benefits of energy saving and carbon reduction to consumers. This kind of information allows consumers to feel assured that adopting the green design product is helpful for reducing pollution, slashing energy consumption, and enhancing their work efficiency and thus have positive evaluations about the product. Their positive evaluations will in turn enhance their purchase intention and increase their green consumption behavior.

2. Results show that among the dimensions of TPB, both "Green perceived behavior control" and "Green subjective norm" have a positive and significant impact on "Green behavioral intention". These findings suggest that businesses should show the environmental labels they have been awarded on their products, provide sufficient information to increase consumers' knowledge of the environmental information of their products, such as energy savings, and influence consumers to feel the pressure to contribute to energy saving from social groups or online communities. All these actions can increase consumers' intention to buy green products under the influence of green subjective norm.

3. It is found that both "Normative conformity" and "Informational conformity" have a significantly positive effect on "Green subjective norm", with the effect of "Normative conformity" being particularly higher. Therefore, businesses are suggested to market their green design displays in online communities that the targeted customers commonly use and also set up a social group or fans group for their green design displays to increase consumers' identification with the group and products. While consumers would avoid being excluded from their social groups, they tend to adopt the products recommended by other members of their social groups. As a result, they have a higher propensity to engage in the perception of subjective norm of buying green design displays.

4. It is indicated that "Government's low-carbon policy" has a significantly positive effect on "Green behavioral intention". Therefore, in promoting a carbon reduction policy, the government can provide subsidies for carbon reduction or implement other supplementary measures to increase consumers' intention to buy green design displays and strengthen the competitive advantage of the display manufacturing industry.

\subsubsection{Analysis of Differences in the Perception of Research Dimensions by Demographic Variables}

1. On average, "female" consumers score significantly higher on the variables from TAM and TPB as well as conformity behavior than male ones. This reveals that female consumers generally more agree that these variables affect consumers' buying of green design displays than male ones. Therefore, this study suggests that businesses explain the environmental benefits of green products on the package of green design displays and in 
the advertisement of green design displays to highlight the characteristics of higher ease of use and higher work efficiency of green products. For male consumers, they can develop a customized green design display and sell it as a bundle with electronic products that are attractive to male consumers. For example, they can bundle the display with a video game console, a laptop computer, an audio system, VR glasses or an audio/video playback system. They can also offer group buying discounts, such as pre-order discount, discount on in-store group buying, and discount for group buying among online community members, to promote consumers' green consumption intention. Eventually, male consumers will have a higher intention to buy green design displays.

2. The analysis by "marital status" shows a higher average score for the TAM dimensions among married consumers than among unmarried or divorced consumers. This suggests that married consumers tend to pay more attention to whether the user interface is easy to understand and use and whether the product can enhance work efficiency when buying a display. Therefore, businesses are suggested to stress the benefits of using green design displays when advertising products among unmarried or divorced consumers. They can differentiate the products for married and unmarried or divorced consumers. For single consumers (unmarried or divorced), they can provide personalized products and special offers to make them believe that the green design displays can be easily used without third-party assistance and also increase their productivity. For example, displays integrated with television, computer or multimedia functions or displays integrated with a smartphone or laptop platform enable consumers to switch functions and perform multiple tasks across different platforms on the same device. When consumers experience the claimed benefits of green consumption, they will have positive evaluations of green design products and have a higher intention towards green consumption. This is a way to promote the actual buying of green design displays.

3. The analysis by "education level" shows that consumers with a college/university score significantly higher on conformity behavior than those with a master/doctorate degree. This suggests that due to having stronger subjective consciousness, consumers with a master/doctorate degree are less likely to perform a behavior as expected by their group members simply because they want to avoid the risk of being excluded from the group. Therefore, when marketing products among this group of consumers, businesses can strengthen the exposure of their products and explain their advantages on social networking platforms or public media. Moreover, they can also cite the suggestions and personal experiences of current users in their marketing materials, which can referenced by people who are recommending their green design displays to consumers with a master/doctorate degree. This may be a viable approach to increase the green subjective norm and induce the green consumption intention among this group of consumers.

4. The analysis by "place of residence" shows that consumers living in Central Taiwan score significantly higher on conformity behavior than those living in Northern and other regions of Taiwan. This implies that compared to consumers in Northern and other regions of Taiwan, those living in Central Taiwan have a higher degree of conformity behavior. This finding suggests that businesses can increase their sales in Northern and other regions of Taiwan by encouraging product recommendation and group buying. When more and more friends, relatives or members of social groups have a higher intention to buy or have adopted green design displays, consumers will be influenced by the consumption behavior of these people to adopt the same or a similar behavior to establish their group identity. This is a way to increase the intention to buy and actual behavior of buying green design displays among consumers in Northern and other regions of Taiwan.

\section{References}

Ajzen, I. (1991) The theory of planned behavior. Organizational Behavior and Human Decision Processes, 50 (2), 179-211. https://doi.org/10.1016/0749-5978 (91)90020-T

Chen, J. Y. (2012). A model of green consumption behavior constructed by the theory of planned behavior. Master Thesis, Department of Business Administration, National Chin-Yi University of Technology, Taichung City, Taiwan.

Chen, P. J. (2012). Use of theory of planned behavior in consumption behavior of Taiwan consumers on U.S. beef. Master Thesis, Department of Food and Beverage Management, University of Kang Ning, Tainan City, Taiwan.

Chen, Y. Z. (2016). Analysis of influence factors on electric vehicle procurement utilizing planned behavior theory. Master Thesis, Department of Industrial Engineering and Enterprise Information, Tunghai University, Taichung City, Taiwan.

Chiao, H. I. (2015). An integration of TAM TPB to investigate factors affecting the replacement intention of smart. Master Thesis, Department of Finance, Southern Taiwan University of Science and Technology, 
Tainan City, Taiwan.

Chung, P. S. (2011). A study on green consumption behavior for carbon-labelled beverages. Master Thesis, International BBA Program in International Business, Chang Jung Christian University, Tainan City, Taiwan.

Davis, F. D. (1989). Perceived usefulness, perceived ease of use, and user acceptance of information technology. MIS Quarterly, 13 (3), 319-340. https://doi.org/10.2307/249008

Hair, J. F., Anderson, R. E., Babin, B. J., \& Black, W. C. (2010). Multivariate data analysis: A global perspective. (Vol. 7). New Jersey: Pearson.

Hair, J. F., Black, W. C., Babin, B. J., Anderson, R. E., \& Tatham, R. L. (2006). Multivariate data analysis (6th ed.). New Jersey: Journal of Abnormal Psychology, 49-74.

Hsiung, C. Y. (2014). An empirical study of the impact of conformity on APP game user intention from TRA and expanded TAM The case of Candy Crush Saga. Master Thesis, Department of Engineering Management, National Cheng Kung University, Tainan City, Taiwan.

Hsu, C. B. (2016). An investigation of students' attitudes of mobile learning for information management major students in vocational high school-A case study of technology acceptance model. Master Thesis, Graduate Institute of Technological and Vocational Education, National Pingtung University of Science and Technology, Pingtung, Taiwan.

Hu, K. H. (2018). A Comparative case study of blue ocean strategy and value innovation of display firms in Taiwan. Master Thesis, Department of Business Management, Tatung University, Taipei City, Taiwan.

Huang, C. H. (2017). The impact of the innovative financial service model of mobile payments on online consumer behavior. Master Thesis, Department of Information Management, National Defense University, Taipei City, Taiwan.

Huang, H. F. (2016). The extended TPB explore the consumption behavioral intentions of organic products. Master Thesis, Department of Marketing and Logistics Management, Southern Taiwan University of Science and Technology, Tainan City, Taiwan.

Huang, S. P. (2013). An investigation on the influential factors of group buying behaviors based on technology acceptance model. Master Thesis, Department of Marketing Management, Takming University of Science and Technology, Taipei City, Taiwan.

Kaiser, H. F. (1974). An index of factorial simplicity. Psychometrika, 39 (1), 31-36.

Kuo, W. H. (2016). A study that investigate consumers product purchase intentions on Taiwan company practice social responsibility. Master Thesis, Department of Public Relations and Advertising, Shih Hsin University, Taipei City, Taiwan.

LEDinside (2018). LEDinside $\ulcorner$ Micro LED Advanced Technology $\lrcorner$ selected article-Quantum dot-based Micro LED screen full color technology (Nov. 8, 2018). Retrieved from https://m.ledinside.com.tw/node/view/35729.html

Liu, C. H. (2008). Relationships between the determinants of consumer usage in the wireless city and telecommunication technologies: The comparisons of Taipei (Taiwan) and Singapore. Master Thesis, Graduate Institute of Management of Technology, Feng Chia University, Taichung City, Taiwan.

Shen, T. Y. (2003). The research on consuming intention affected by government housing policy, media \& customers' preference - A case study to Taichung county \& city. Master Thesis, Department of Business Administration, Chaoyang University of Technology, Taichung City, Taiwan.

Tu, Y. X. (2009). The new trend of environmental protection and energy saving for flat panel displays. Photonics Industry \& Technology Development Association Journal, 81, 18-21.

Wu, W. Y. (2019). Business research methods. Taipei City: Hwa Tai Publishing Co., Ltd.

Yang, C. Y. (2012). Green consumer factors of consumers to purchase behavioral intentions-Green $3 C$ products. Master Thesis, Department of Information Management, National Taitung University, Taitung City, Taiwan.

Yeh, W. L. (2007). Green design study on the mechanism in protecting LCD-TV panel. Master Thesis, Department of Mechanical Engineering, National Cheng Kung University, Tainan City, Taiwan. 


\section{Copyrights}

Copyright for this article is retained by the author (s), with first publication rights granted to the journal.

This is an open-access article distributed under the terms and conditions of the Creative Commons Attribution license (http://creativecommons.org/licenses/by/4.0/). 